\title{
TRIM28 congenital predisposition to Wilms' tumor: novel mutations and presentation in a sibling pair
}

\author{
Colin Moore, ${ }^{1,2,3}$ Hector Monforte, ${ }^{4}$ Jamie K. Teer ${ }^{5}$ Yonghong Zhang, ${ }^{5}$ \\ Sean Yoder, ${ }^{6}$ Andrew S. Brohl, ${ }^{7}$ and Damon R. Reed ${ }^{1,2,7,8}$ \\ ${ }^{1}$ Adolescent and Young Adult Program, ${ }^{2}$ Department of Individualized Cancer Management, H. Lee Moffitt \\ Cancer Center and Research Institute, Tampa, Florida 33612, USA; ${ }^{3}$ Center for Cancer and Blood Disorders, \\ ${ }^{4}$ Department of Anatomic Pathology, Johns Hopkins All Children's Hospital, St. Petersburg, Florida 33701, \\ USA; ${ }^{5}$ Department of Biostatistics and Bioinformatics, ${ }^{6}$ Molecular Genomics Core Facility, ${ }^{7}$ Sarcoma \\ Department, ${ }^{8}$ Cancer Biology and Evolution Program, H. Lee Moffitt Cancer Center and Research Institute, \\ Tampa, Florida 33612, USA
}

\begin{abstract}
Wilms' tumor is the most common renal malignancy in children. In addition to staging, molecular risk stratification, such as loss of heterozygosity $(\mathrm{LOH})$ in Chromosomes 1 and 16 , is being increasingly used. Although genetic predisposition syndromes have been well-characterized in some Wilms' tumors, recent sequencing and biology efforts are expanding the classification of this malignancy. Here we present a case of siblings with remarkably similar presentations of bilateral Wilms' tumor at $\sim 12$ mo of age. Thorough exam after the younger sibling was diagnosed did not reveal any signs to suggest one of the known Wilms' predisposition syndromes. Both were treated with standard therapies with good response and long-term sustained complete remission of 53 and $97 \mathrm{mo}$, respectively. Wholeexome sequencing was performed on a tumor sample from each patient and matched blood from one, revealing a shared truncation mutation of TRIM28 in all three samples with heterozygosity in the germline sample. TRIM28 loss has been recently implicated in early-stage Wilms' tumors with epithelioid morphology. These siblings expand the phenotype for presentation with multifocal disease with retained excellent response to standard therapy.
\end{abstract}

Corresponding author: colin.moore@moffitt.org

(c) 2020 Moore et al. This article is distributed under the terms of the Creative Commons Attribution-NonCommercial License, which permits reuse and redistribution, except for commercial purposes, provided that the original author and source are credited.

Ontology term: nephroblastoma (Wilms tumor)

Published by Cold Spring Harbor Laboratory Press

doi:10.1101/mcs.a004796
[Supplemental material is available for this article.]

\section{INTRODUCTION}

Wilms' tumor is the most common form of childhood malignancy arising from the kidney, a site accounting for $7 \%$ of childhood cancers (Dome et al. 2013). In rare cases, Wilms' arises in the context of identifiable genetic syndromes (Dome and Huff 1993). Recent large genomic efforts in Wilms' tumors have uncovered recurrently mutated genes at frequencies of $<20 \%$ including DGCR8, DROSHA, and SIX (Walz et al. 2015). Individual cases have revealed novel mechanisms of inherited Wilms' predisposition more recently (Micale et al. 2016). We report a sibling pair with a remarkably similar presentation of bilateral Wilms' tumor presenting near the first year of life and proposed to investigate the somatic and tumor landscape toward a better understanding of the genetic mechanisms that lead to the development of this phenotype.

The primary objective of this project was to perform comprehensive molecular profiling of tumors from two siblings that developed bilateral Wilms' tumor in infancy without a known 
genetic syndrome. The hypothesis was that these siblings share a genetic predisposition that cannot be clinically determined and that may provide a novel insight into the biology of Wilms' tumor.

\section{RESULTS}

\section{Clinical Presentation}

Patient 1 in our cohort is a female born at 32 wk gestation without major complications who presented at 12 mo of age with asymptomatic bilateral masses palpable in the abdomen. Initial computed tomography (CT) scan evaluations revealed bilateral intrarenal masses. In the left kidney there were three masses, the largest being $8.1 \times 7.7 \mathrm{~cm}$, and in the right a solitary mass measuring $7.4 \times 6.7 \mathrm{~cm}$ (Fig. 1A). No metastatic lesions outside the kidneys were identified. The patient was diagnosed with presumed bilateral Wilms' tumor and was initiated on 6 wk of vincristine, actinomycin-D (dactinomycin), and doxorubicin (VAD) therapy with good response, followed by an additional 6 wk prior to resection. She underwent full left nephrectomy and right partial nephrectomy with final classification of clinical stage $V$ because of bilateral involvement and surgical stage I with complete resection. Pathology of nephrectomy specimen revealed two circumscribed and encapsulated tumors, the larger $4 \mathrm{~cm}$ and the smaller $1 \mathrm{~cm}$ in greatest diameter, and one circumscribed $3-\mathrm{cm}$ nodule of similar firm and homogenous solid appearance resected from the lower pole in the contralateral kidney; no macrocysts, necrosis, or hemorrhage were noted. Morphologically, all tumors showed triphasic nephroblastoma with predominant epithelial cytodifferentiation, including glomeruloid, tubular, and papillary structures, conspicuous microcysts throughout, and dystrophic calcification. Isolated foci of nodular confluent fibrosis were noted suggestive of regressed tumor field area. Mitotic activity was inconspicuous and no residual blastemal primitive areas or anaplasia were present (Fig. 2). Final International Society of Pediatric Oncology (SIOP) posttherapy classification of the tumor was mixed histology. The patient completed a further 12 wk of therapy per EE-4A without radiation and remains in complete remission 97 mo off therapy (Fig. 3).

The younger female sibling, Patient 2, was born at 34 wk gestation complicated by apnea of prematurity and presented at 14 mo of age with asymptomatic bilateral masses palpable in the abdomen. Initial CT scan evaluations revealed bilateral intrarenal masses. In the left kidney there were two masses, the largest being $6 \times 4.9 \mathrm{~cm}$, and in the right three masses,
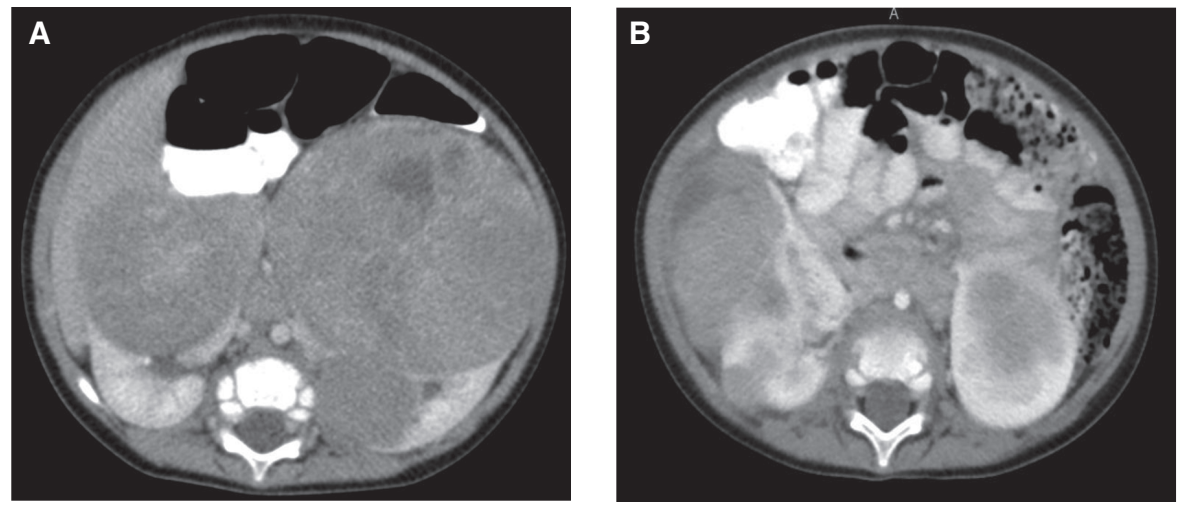

Figure 1. Radiologic presentation. Upon initial presentation, axial contrast-enhanced computed tomography (CT) demonstrates large bilateral masses within the kidney for Patient $1(A)$ and Patient $2(B)$ at diagnosis. 

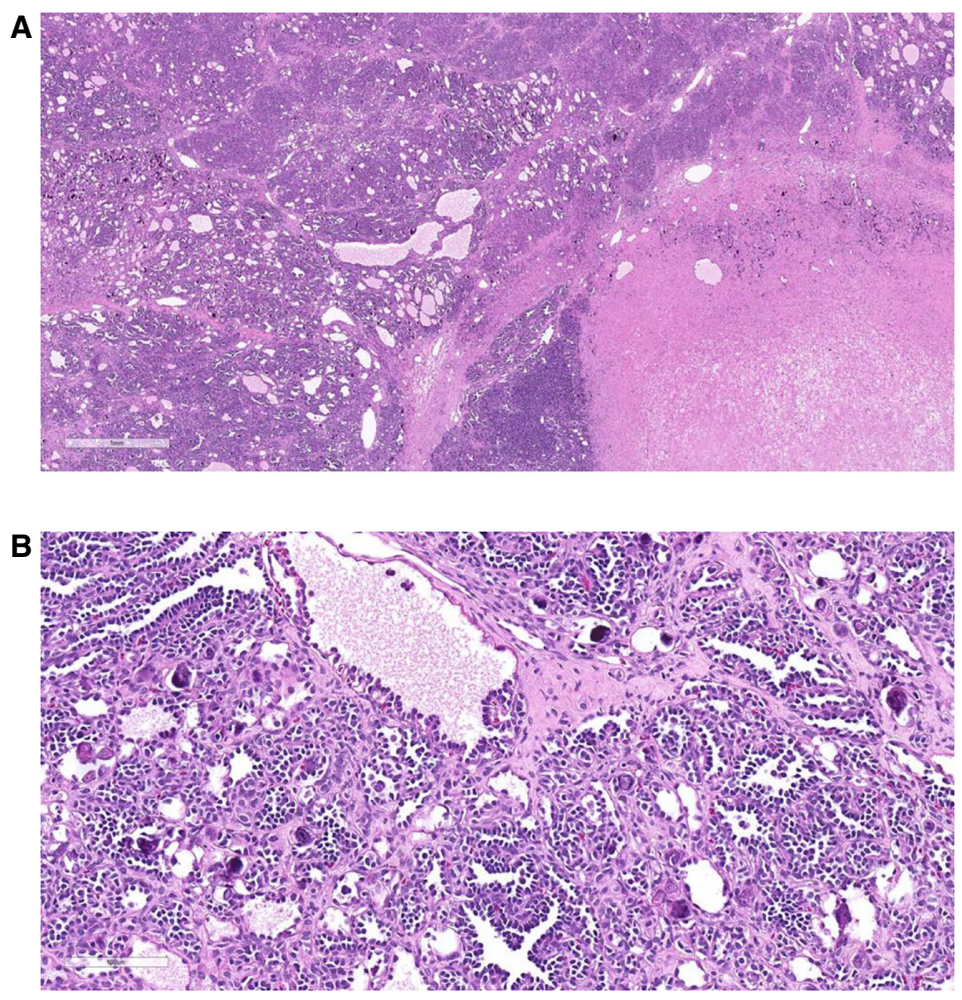

Figure 2. Histologic analysis of tumor specimen. (A) $20 \times$ and (B) $40 \times$ magnification revealed triphasic nephroblastoma with predominant epithelial cytodifferentiation, including glomeruloid, tubular, and papillary structures, conspicuous microcysts throughout, and dystrophic calcification. Isolated foci of nodular confluent fibrosis ( $A$, right lower) are suggestive of regressed tumor area. No areas of anaplasia were noted.
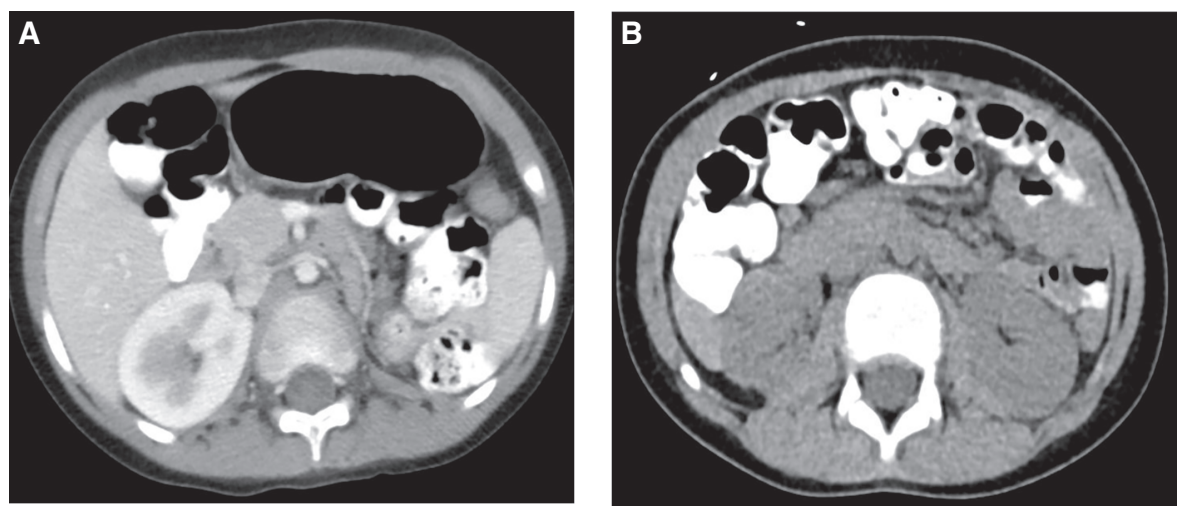

Figure 3. Radiologic response to therapy. (A) Axial contrast-enhanced CT demonstrates postoperative changes following chemotherapy and full left nephrectomy and right partial nephrectomy in case 1, three years off therapy. (B) Axial non-contrast-enhanced CT due to renal toxicity demonstrates postoperative changes following chemotherapy, bilateral flank irradiation, and bilateral partial nephrectomies in Case 2, three years off therapy. 
the largest measuring $6 \times 4.9 \mathrm{~cm}$ (Fig. 1B). No metastatic lesions outside the kidneys were identified. Patient was diagnosed with presumed bilateral Wilms' tumor and was initiated on 6 wk of VAD therapy with good response, followed by an additional 6 wk prior to resection. Her treatment was complicated by vocal cord paralysis requiring reduction in vincristine dosing. She underwent bilateral partial nephrectomy with final clinical stage $\mathrm{V}$ because of bilateral involvement and surgical stage III with positive surgical margins. Pathology of the resected tumor specimens consisted of six circumscribed encapsulated tumors, three from each kidney, ranging from $0.9 \mathrm{~cm}$ to $4.6 \mathrm{~cm}$ in greatest diameter. Grossly composed of firm and homogeneous appearing treated tumor, no macrocysts, hemorrhage, or necrosis were noted. The morphology was identical to the treated tumors described in the older sibling, and again the SIOP posttherapy classification of the tumor was mixed histology. The patient proceeded to bilateral flank radiation because of positive surgical margins and completed a further $12 \mathrm{wk}$ of therapy per DD-4A. She remains in complete remission 53 mo off therapy (Fig. 3).

\section{Genomic Analyses}

Based on nearly identical disease presentation, we suspected an inherited variant may be present that predisposed to Wilms' tumors. Initial efforts therefore focused on identification of a potentially pathogenic germline mutation (i.e., found in all samples). Of shared variants between all three samples and after filtering based on annotations we identified a single putatively pathogenic mutation, which resulted in a truncation of TRIM28 (Bunch and Calderwood 2015; Kim et al. 2015; Czerwinska et al. 2017; Liu et al. 2017; Halliday et al. 2018). The TRIM28 mutation is predicted to introduce stop codon at glutamine 701 resulting in the loss of 135 carboxy-terminal amino acids (Table 1). The truncated region includes a TIF1-like bromodomain and a number of putative phosphorylation and acetylation sites (https://www.ncbi.nlm.nih.gov/protein/5032179). This variant is not observed in 1000 Genomes, Exome Variant Server, or Exome Aggregation Consortium (ExAC). Indeed, no TRIM28 loss of function variants are observed in ExAC, leading to a calculated probability of loss of function (LOF) intolerance of 1 , which suggests the gene is completely intolerant of LOF variation.

Interestingly, the single tumor samples from both patients have high alternate variant allele frequency (VAF) at the TRIM28 position (93.8\%, 97.4\%), suggesting that the variant is homozygous in the tumors. The allele frequency in Patient 2's germline sample is $63.6 \%$, suggesting that the variant is heterozygous in the germline. Plotting allele frequency of all variants across Chromosome 19 in both samples shows a loss of allele frequencies of $~ 50 \%$ starting in the $q$ arms of both patients' tumor samples and including the TRIM28 locus at the end of the chromosome. The expected $50 \%$ allele frequency indicative of heterozygosity is observed in the germline sample. This suggests that a loss of heterozygosity (LOH) occurred in each tumor sample. The breakpoints appear to be different in each patient, supporting the notion of a separate somatic event (Fig. 4). Furthermore, somatic copy-number analysis did not show a Chromosome $19 \mathrm{q}$ arm loss of coverage across the LOH region in either patient tumor sample, suggesting this is a copy-neutral LOH event (Fig. 5).

\begin{tabular}{|c|c|c|c|c|c|c|c|}
\hline Gene & Chromosome & $\begin{array}{l}\text { HGVS DNA } \\
\text { reference }\end{array}$ & $\begin{array}{l}\text { HGVS protein } \\
\text { reference }\end{array}$ & $\begin{array}{l}\text { Variant } \\
\text { type }\end{array}$ & $\begin{array}{c}\text { Predicted effect } \\
\text { (substitution, } \\
\text { deletion, etc.) }\end{array}$ & $\begin{array}{l}\text { dbSNP/ } \\
\text { dbVar ID }\end{array}$ & $\begin{array}{c}\text { Genotype } \\
\text { (heterozygous/ } \\
\text { homozygous) }\end{array}$ \\
\hline TRIM28 & 19 & $\begin{array}{l}\text { NC_000019.9: } \\
\text { g.59061222C >T }\end{array}$ & $\begin{array}{l}\text { p.NP_005753.1: } \\
\text { p.Gln701* }\end{array}$ & $\begin{array}{l}\text { Stop- } \\
\text { gain }\end{array}$ & Substitution & - & Heterozygous \\
\hline
\end{tabular}




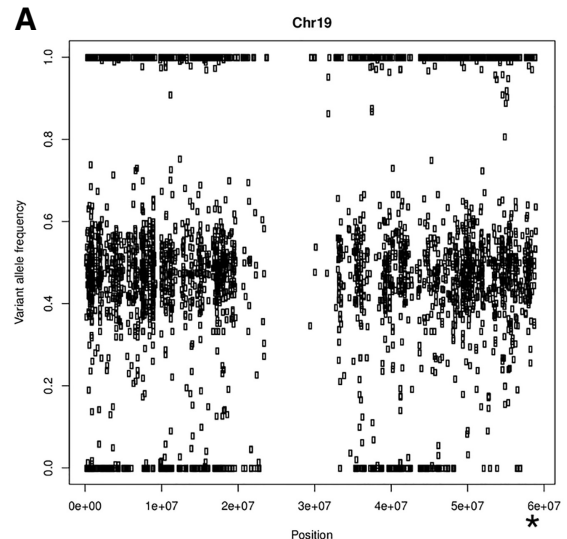

Patient 2 Blood

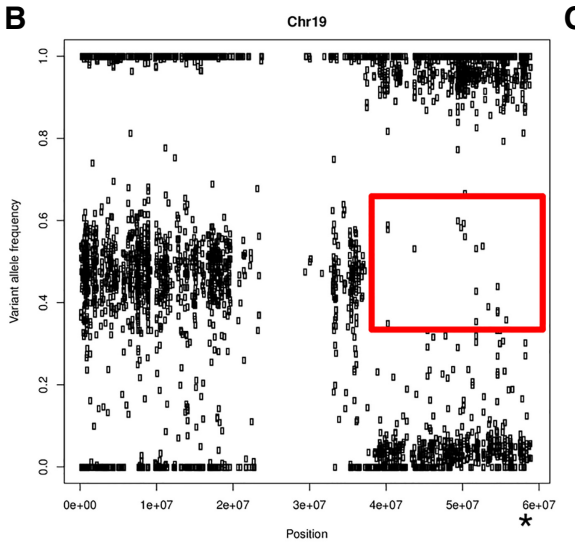

Patient 2 Tumor

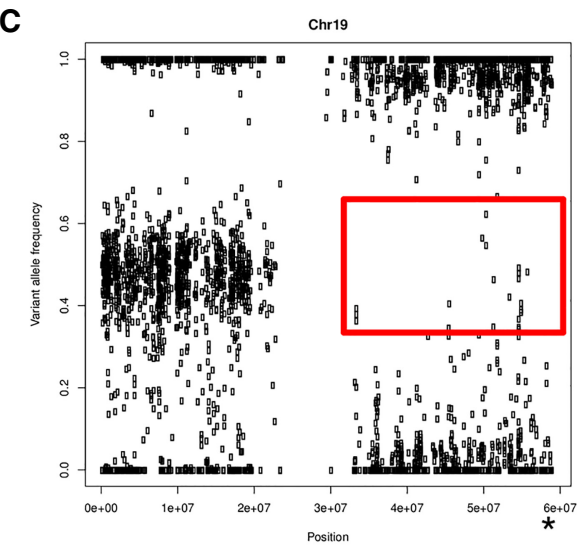

Patient 1 Tumor

Figure 4. Chromosome 19 allele frequencies at all variant positions in (A) Patient 2's blood, (B) Patient 2's tumor, and (C) Patient 1's tumor. Red boxes indicate regions where heterozygosity ( $50 \%$ allele frequency) is no longer observed. The $y$-axis is the allele frequency (alternate allele reads/total reads); the $x$-axis is the position on Chromosome 19. The asterisk (*) indicates the approximate position of TRIM28.

19

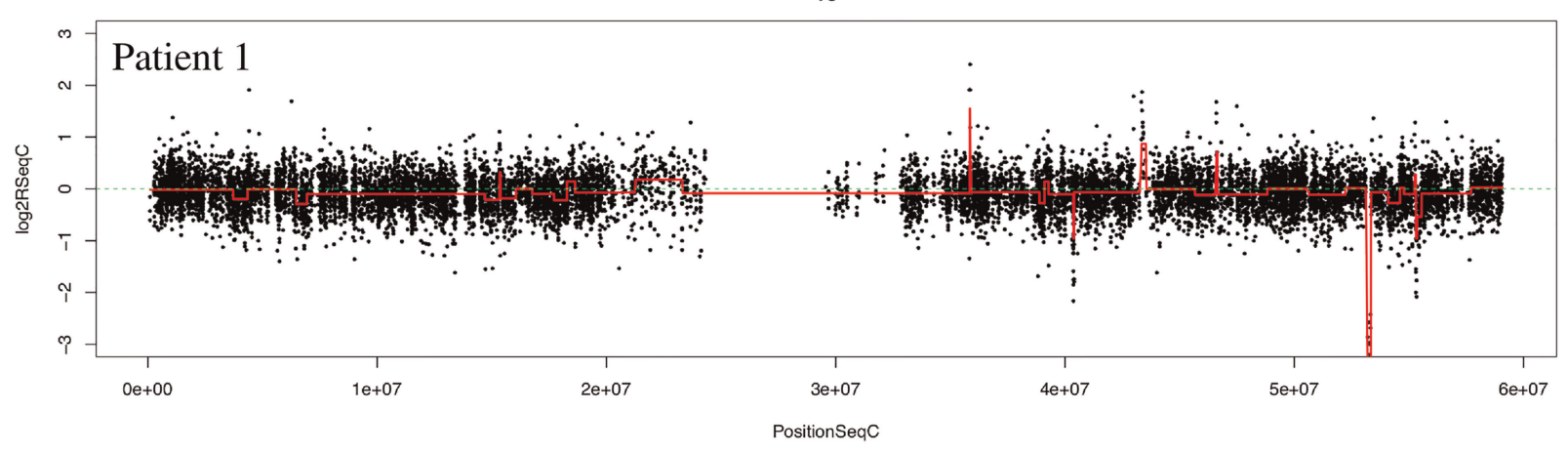

19

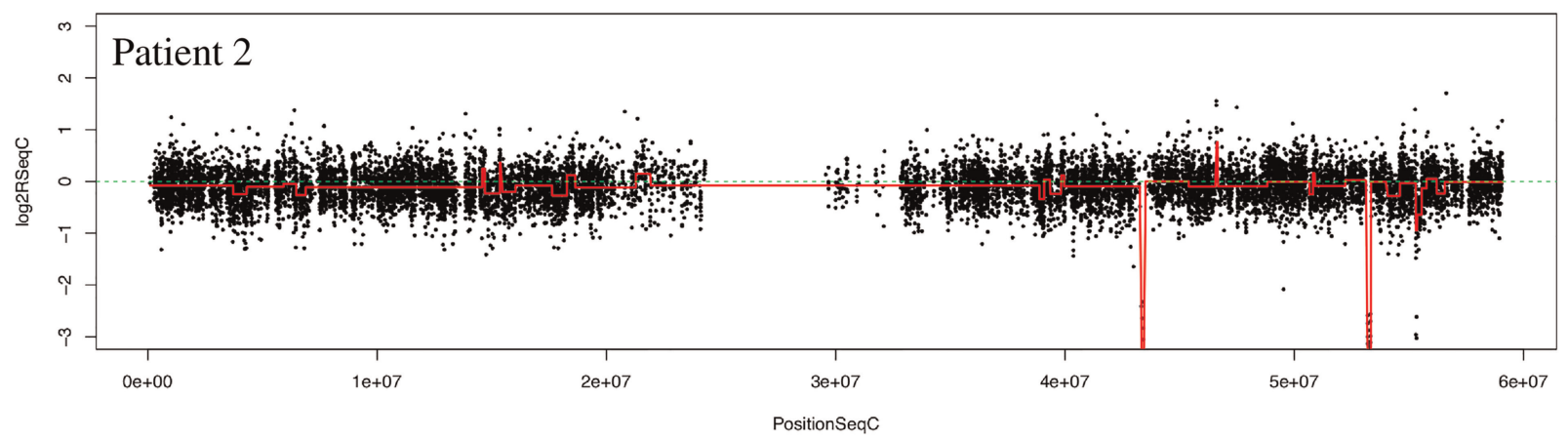

Figure 5. Chromosome 19 somatic copy-number changes for tumor samples. Note that Patient 1's tumor was compared to Patient 2's blood for copy-number variation (CNV) detection. The $y$-axis is the $\log _{2}$ read depth ratio; the $x$-axis is the Chromosome 19 position. Note the average $\log _{2}$ depth ratio on the $q$ arm is 0 , indicating no large copy-number change. 
In addition to the putatively pathogenic germline TRIM28 mutation with evidence of $\mathrm{LOH}$ in both tumor samples, we evaluated the sequencing data for additional potentially oncogenic mutations. From Patient 2's germline-matched tumor sample, we identified 59 highconfidence somatic mutations, for a mutational frequency of 0.90 mutations $/ \mathrm{Mb}$. Of these, nine were protein-altering. From the tumor with unmatched sequencing, we identified 5,140 variants with minimum genotype quality of 15 , excluding Tranche 100 variants, and excluding variants observed at $1 \%$ or more in 1000 Genomes. Of these, 793 were protein-altering. Between both tumors, we identified 26 variants with possible oncogenic function based on annotations. Splicing variants were observed in RECQL4 (all samples) and ATM (one in all samples; one in Patient 2 tumor and germline). Two stop-gain variants were observed in CR1 in Patient 1's tumor (Supplemental Table S1).

Somatic copy-number variants (CNVs) were identified by comparing each tumor sample to one patient's matched germline sample. The unmatched pair shows 8.3 MB of CNVs (26 events), whereas the matched pair shows $2.2 \mathrm{MB}$ (12 events). Affected genes were cross-referenced with the Catalogue of Somatic Mutations in Cancer (COSMIC) Cancer Gene Census, and a single copy amplification of HIST1H3B was observed in Patient 2.

\section{DISCUSSION}

Driver mutations have long been sought to help understand the pathogenesis of Wilms' tumor. A lack of identification of the phenotype of the more common Wilms' tumor predisposition mutations in our patients led us to the hypothesis that they harbored a novel somatic predisposition gene. Although during the interval from posing this hypothesis to writing up this manuscript witnessed tremendous gains in genomic understanding of Wilms' tumor including multiple publications demonstrating TRIM28 predisposition to Wilms', our sibling pair provides additional detail, a novel truncation of the carboxy-terminal 145 amino acids, and a more pronounced clinical presentation of bilateral, multifocal disease. This nonsense mutation may either produce a truncated protein or lead to nonsense-mediated decay, as we do not have any evidence of the truncated protein being detected. This is the most carboxy-terminal mutation reported in the literature to date and may help toward understanding the minimal essential loss required toward tumor development. The genetic variant predicted to result in TRIM28 Q701X was observed in all samples. This variant was heterozygous in the blood sample of Patient 2 and homozygous in both tumor samples. Allele frequency and copy-number analysis suggest a germline heterozygous mutation became homozygous because of a copy-neutral loss of the functional allele. Interestingly, the LOH breakpoint was slightly different in the two siblings, but included most of the $q$ arm of Chromosome 19 (despite the fact that TRIM28 is located at the extreme end of the chromosome). Patient 2 had a matched tumor/normal sample pair, enabling calculation of the somatic mutation rate of 0.9 mutations/MB. This is a lower mutation rate, although not as low as some childhood cancers (Alexandrov et al. 2013). CNV analysis showed low genomic fraction affected by copynumber change $(0.073 \%-0.28 \%)$, lower than the average cancer (Beroukhim et al. 2010). These results suggest Wilms' tumors have lower single-nucleotide and copy-number change alterations than many other tumors. Although we observed single-nucleotide and copy-number changes in known cancer genes, the functional impact of these mutations was not obvious and requires further consideration in larger cohorts of Wilms' tumors.

Previous reports of TRIM28-associated Wilms' tumor have shown a diverse makeup of mutations and associated proteins, while revealing close similarities in clinical and histological presentations. The Children's Oncology Group (COG) and TARGET initiative evaluation produced a comprehensive review of the genetic variation in Wilms' tumor and still only noted 440 of the 651 tumors sampled in their analysis to carry mutations that were predicted to 
be damaging (Gadd et al. 2017). TRIM28 was identified in this study as a rarer mutation, and inactivation of TRIM28 has been recently reported as a recurrent genomic feature of a subset of Wilms' tumor with early age of onset and good prognosis, including as a germline event in several familial cases (Armstrong et al. 2018; Diets et al. 2019; Mahamdallie et al. 2019). A cohort of five patients with TRIM28 mutations diagnosed between 7 and $39 \mathrm{mo}$, including two sibling pairs, was previously characterized (Halliday et al. 2018). The authors identified three primary frameshift mutations: c.525_526del germline mutation with loss of heterozygosity and retention of the variant allele in both tumors in the first sibling pair, c.1746_1747delinsC germline mutation with loss of heterozygosity and retention of the variant allele in both tumors in the second sibling pair, and c.1935delinsGA somatic mutation combined with exon 1 methylation in tumor in the final patient. The $\mathrm{LOH}$ in all tumors lead to the conclusion that a complete loss of TRIM28 was present in the tumors, and this was confirmed on histologic analysis. The six localized tumors all demonstrated a predominant epithelial component at the time of resection and all patients had superior outcomes with all alive at $>19 \mathrm{yr}$ since diagnosis. An additional cohort of patients was reported by COG identifying nine unrelated patients (Armstrong et al. 2018). These patients had similar age distribution of the previous cohorts, all shared epithelial histology, and none of the patients developed relapsed disease. This study also identified novel somatic frameshift mutations along with nonsense and three splice site mutations within TRIM28. Only one of the nine patients was proven to have a germline component, which consisted of a nonsense mutation leading to a protein change of $p$.Arg487x. This nonsense mutation and protein change was identified as well in an unrelated patient. A third analysis focused initially on two sibling pairs in which one sibling had unilateral disease and the other had bilateral disease in both pairs. After identification of TRIM28 mutations, it then expanded its cohort to screen a further 269 patients with Wilms' tumor and identified an additional seven cases with TRIM28 mutations. Germline mutations were identified in eight of the nine total patients, and LOH was noted in all but one of the germline cases. In both the familial cases and the sporadic cases, the predominant pathology was epithelial in 11 of the 12 cases and was seen in low-risk patients. Each sibling pair showed its own unique TRIM28 mutation, and all sporadic cases had their own unique mutations identified as well (Diets et al. 2019).

In a further analysis of potential Wilms' tumor predisposition syndromes, a recent study identified 17 individuals from 13 families with pathogenic truncating mutations of TRIM28 (Mahamdallie et al. 2019). The predominant histology in these patients was again identified as epithelial, and all but one survived their disease. Unlike the prior studies, there were some patients who shared previously identified genetic and protein changes. Three siblings shared a mutation in c.1746_1747delinsC seen in the first cohort discussed, and one patient was identified that shared protein change in p.Arg487X similar to the COG study. A summary of the gene mutations and protein changes identified in our and the related studies can be found in Table 2.

Similar to these prior cohorts, our patients were both identified at a young age and had an excellent outcome despite bilateral disease at presentation.

TRIM28, also known as KAP1 and TIF1, was initially discovered as a partner of the Krüppel-associated box domain-containing zinc finger transcription factors (KRAB-ANFs) by multiple institutions in the mid-1990s (Friedman et al. 1996; Kim et al. 1996; Moosmann et al. 1996). Its function has been further elucidated since its initial defined role with KRAB factors in gene repression (lyengar and Farnham 2011). It has displayed critical roles in transcriptional control and DNA repair via stabilizing the pausing of RNA polymerase II close to the transcriptional start, leading to its accumulation preparing genes for induction (Bunch and Calderwood 2015). Further analysis of TRIM28 has more clearly defined its role in ontogenesis in a variety of cancers. Through polyubiquitination it generates degradation of $553, A M P K$, and FBP1, leading to suppression of apoptosis, promotion of 
Table 2. Summary of TRIM28 mutations and associated protein changes in Wilms' tumor patients

\begin{tabular}{|c|c|c|}
\hline Study & Gene mutation & Protein change \\
\hline This study & c. $2101 \mathrm{C}>\mathrm{T}$ & p.G $\ln 701 x$ \\
\hline Halliday et al. 2018 & $\begin{array}{l}\text { c.525_526del } \\
\text { c. } 1746 \text { 1747delinsC } \\
\text { c. } 1935 \text { delinsGA and exon } 1 \text { methylation }\end{array}$ & $\begin{array}{l}\text { p.Glu175Aspfs*29 } \\
\text { p.Glu583Argfs*93 } \\
\text { p.Phe645Leufs*30 }\end{array}$ \\
\hline Armstrong et al. 2018 & $\begin{array}{l}\text { g.59056439_59056440 insCGGCGGGG) } \\
\text { g.59056466T > G } \\
\text { g.59058844C }>T \\
\text { g.59058853C }>\text { T } \\
\text { g.59059081G > A } \\
\text { g.59059081G }>A \\
\text { g.59060404C > T } \\
\text { g.59060970_59060971 delTT }\end{array}$ & $\begin{array}{l}\text { p.Gln233x } \\
- \\
\text { p.Arg230x } \\
\text { p.Asp105fs } \\
- \\
- \\
\text { p.Arg487x } \\
\text { p.Phe645fs }\end{array}$ \\
\hline Diets et al. 2019 & $\begin{array}{l}\text { c. } 175 \mathrm{del} \\
\text { c. } 246 \_247 \mathrm{del} \\
\text { c. } 520 \_523 \mathrm{del} \\
\text { c. } 586+2 \mathrm{~T}>\mathrm{C} \\
\text { c. } 847 \mathrm{C}>\mathrm{T} \\
\text { c. } 1015 \mathrm{C}>\mathrm{T} \\
\text { c. } 1162 \_1162 \text { insGA } \\
\text { c. } 1562 \_1569 \text { dup } \\
\text { c. } 1629 \text { del }\end{array}$ & $\begin{array}{l}\text { p.Leu59Trpfs*34 } \\
\text { p.Cys83Phefs*6 } \\
\text { p.Cys174Argfs*4 } \\
\text { p.Cys152Glyfs*50 } \\
\text { p.Gln283* } \\
\text { pGln339* } \\
\text { p.Met389Argfs*2 } \\
\text { p.Arg524Leufs*155 } \\
\text { p.Ala544Profs*132 }\end{array}$ \\
\hline Mahamdallie et al. 2019 & $\begin{array}{l}\text { 209_210delAG } \\
\text { 239_245del7 } \\
\text { 429dupC } \\
525 \_526 \text { delGA } \\
688 \mathrm{C} \rightarrow \mathrm{T} \\
840-2 \mathrm{~A} \rightarrow \mathrm{G} \\
929 \mathrm{G} \rightarrow \mathrm{A} \\
1085 \mathrm{~T} \rightarrow \mathrm{A} \\
1150 \mathrm{G} \rightarrow \mathrm{T} \\
1250 \mathrm{C} \rightarrow \mathrm{A} \\
1300 \_1301 \text { dupAA } \\
\text { 1459C } \rightarrow \mathrm{T} \\
1746 \_1747 \text { delinsC } \\
\text { 1957delC De } \\
2508 \mathrm{~A} \rightarrow \mathrm{G}\end{array}$ & $\begin{array}{l}- \\
- \\
- \\
- \\
\text { p.Arg230X } \\
- \\
\text { p.Gly310Asp } \\
\text { p.Leu362X } \\
\text { p.Glu384X } \\
\text { p.Ser417X } \\
- \\
\text { p.Arg487X } \\
- \\
- \\
\text { p.X836TrpextX? }\end{array}$ \\
\hline
\end{tabular}

tumor cell survival, down-regulation of autophagy, and stimulation of the Warburg effect (Czerwinska et al. 2017). It has been further revealed through HDAC1-mediated deacetylation in p53-null cells to suppress e2F1-mediated apoptosis after DNA damage (Chen et al. 2012). These analyses of the oncogenic and tumor-suppressive roles of TRIM28 have been broad-reaching across multiple cancers including brain, breast, gastric, and pancreatic tumors and have focused on high levels of expression in these cancer types. Recent studies have looked specifically into TRIM28's role in Wilms' tumor as LOF appears to be more critical as the majority of tumors express $\mathrm{LOH}$.

In the normal developing kidney, TRIM28 is active during early embryonic development in both kidney branching and morphogenesis (Cammas et al. 2000). In a tumor-suppressor capacity, TRIM28 has been shown to coimmunoprecipitate in the nucleus with WTX, a gene commonly inactivated in Wilms' tumors, via modulating its chromatin binding and coregulating the expression of DNA repeat elements. This effect has suggested that TRIM28 plays a role in epigenetic silencing and could contribute to its activity in oncogenesis and regulation 
of cellular differentiation as well (Kim et al. 2015). Similarly, with respect to cellular differentiation, TRIM28 has been shown to regulate epithelial-to-mesenchymal transition (EMT) in the embryo, and when it is up-regulated in adult cancers, it has been implicated in promoting carcinoma invasion and metastasis (Czerwinska et al. 2017). The loss of this function through the absence of TRIM28 may impact the lineage-specific development in the kidney and lead to an oncogenic proliferation of epithelial cells. This can be evident based on the high prevalence of epithelial predominant histology in the studied tumors with TRIM28 LOH.

In summary, we report a case of siblings with bilateral Wilms' tumor with congenital TRIM28 heterozygous truncation and LOH in the tumor. Both presented with diffuse disease but have had excellent clinical courses. While ongoing analysis searches for distinct driver mutations in Wilms' tumor, further biologic studies should evaluate this gene outside of low-stage disease and may be able to identify patients with more favorable prognoses with diffuse presentation, perhaps in stage $\mathrm{V}$ patients without extrarenal metastases.

\section{METHODS}

Tissue acquisition was through pedsTCC, MCC17319 open at both Moffitt Cancer Center and Johns Hopkins/All Children's Hospitals, and both parents consented to this study. A chart review and sequencing analysis were conducted under IRB approval (MCC50205, University of South Florida IRB). To further evaluate our patients to identify a possible inherited predisposition for development of Wilms' tumor, we performed whole-exome sequencing (Agilent XT Clinical Research Exome) on peripheral blood collected in remission and from the largest resected tumor from each kidney in the patients after $12 \mathrm{wk}$ of neoadjuvant VAD from each of the siblings. Sequence coverage data can be found in Supplemental Table S2. Paired-end sequencing was performed on Illumina NextSeq $500(76 \times 2)$ instrument, generating an average of $69,114,554$ total read pairs in the tumor samples and $44,395,933$ read pairs in the germline sample, resulting in $111.8 \times$ (tumor) and $77.1 \times$ (germline) mean coverage across the capture region after mapping and duplicate sequence removal. Some $99.2 \%$ (tumor) and $98.8 \%$ (germline) of targeted bases achieved at least 10x depth of coverage. The Burrows-Wheeler Aligner was used to align sequence reads to the human reference (Li and Durbin 2009). The Genome Analysis Toolkit was used for insertion/deletion realignment, quality score recalibration, and identification of single-nucleotide and insertion/deletion variants across all samples (DePristo et al. 2011). Variants in the leastsensitive tranche (Tranche99.90to100.0) were excluded, as were variants with genotype quality of $<15$. Tumor-specific mutations were separately identified with Strelka (Saunders et al. 2012) and MuTect (Cibulskis et al. 2013). We excluded common inherited variants by retaining those variants with minor allele frequency (MAF) $<0.01$ in the 1000 Genomes Project. To further limit our findings to those most likely to be oncogenic, we utilized curated databases including the COSMIC Cancer Gene Census (Sondka et al. 2018) (downloaded 7/2019), the Exome Variant Server (http://evs.gs.washington.edu/EVS/), and ExAC (Lek et al. 2016) to manually review variants for functional consequence and known status as an oncogene/tumor-suppressor gene. Tumor-specific copy-number alterations were detected using EXCAVATOR (Magi et al. 2013). Variants with possible oncogenic function were defined as follows: protein altering, high quality (not Tranche99.90to100.0, GQ $\geq 15$, 1000 Genomes $<1 \%$, ESP AA or EA $<1 \%$ ). Tier1 variants were observed in COSMIC v68 in five or more samples $(n=12)$ or as truncation variants in COSMIC Cancer Census Tier 1 tumor-suppressor genes (TSGs) ( $n=3$ ). Tier2 variants included PolyPhen status of "probably damaging" in any Cancer Census gene $(n=11)$ or truncating mutations in Census Tier 2 TSGs $(n=0)$. 
Competing Interest Statement

The authors have declared no competing interest.

Received September 17, 2019; accepted in revised form April 23, 2020.

\section{ADDITIONAL INFORMATION}

\section{Data Deposition and Access}

The full data generated in the course of this work are available upon request from our institution. The variant was deposited in ClinVar (https://www.ncbi.nlm.nih.gov/clinvar/) and can be found under accession number VCV000973190.1.

\section{Ethics Statement}

The study was approved by the IRB of the University of South Florida, protocol MCC50205. Tissue acquisition was through pedsTCC, MCC17319. We have obtained consent to publish from the parents in this sibling case report.

\section{Author Contributions}

J.K.T., A.S.B., S.Y., Y.Z., H.M., and D.R.R. made substantial contributions to conception and design, acquisition of data, and analysis and interpretation of data. C.M., H.M., J.K.T., A.S.B., and D.R.R. were involved in drafting the manuscript or revising it critically. All authors gave final approval for this version of the manuscript to be published and all agreed to be accountable.

\section{Funding}

Funding was provided by the National Pediatric Cancer Foundation (www.nationalpcf.org). Our study received assistance from the Tissue Core, Molecular Genomics Core, and Cancer Informatics Core Facilities at the H. Lee Moffitt Cancer Center and Research Institute, and National Cancer Institute (NCl)-designated Comprehensive Cancer Center, supported under National Institutes of Health (NIH) grant P30-CA76292. The funding body played no role in the design, conduct, interpretation, or writing of this research and manuscript.

\section{REFERENCES}

Alexandrov LB, Nik-Zainal S, Wedge DC, Aparicio SA, Behjati S, Biankin AV, Bignell GR, Bolli N, Borg A, Børresen-Dale AL, et al. 2013. Signatures of mutational processes in human cancer. Nature 500: 415421. doi:10.1038/nature12477

Armstrong AE, Gadd S, Huff V, Gerhard DS, Dome JS, Perlman EJ. 2018. A unique subset of low-risk Wilms tumors is characterized by loss of function of TRIM28 (KAP1), a gene critical in early renal development: a Children's Oncology Group study. PLoS One 13: e0208936. doi:10.1371/journal.pone.0208936

Beroukhim R, Mermel CH, Porter D, Wei G, Raychaudhuri S, Donovan J, Barretina J, Boehm JS, Dobson J, Urashima M, et al. 2010. The landscape of somatic copynumber alteration across human cancers. Nature 463: 899-905. doi:10.1038/nature08822

Bunch H, Calderwood SK. 2015. TRIM28 as a novel transcriptional elongation factor. BMC Mol Biol 16: 14. doi:10.1186/s12867-015-0040-x

Cammas F, Mark M, Dolle P, Dierich A, Chambon P, Losson R. 2000. Mice lacking the transcriptional corepressor TIF1 $\beta$ are defective in early postimplantation development. Development 127: 2955-2963.

Chen L, Chen DT, Kurtyka C, Rawal B, Fulp WJ, Haura EB, Cress WD. 2012. Tripartite motif containing 28 (Trim28) can regulate cell proliferation by bridging HDAC1/E2F interactions. J Biol Chem 287: 4010640118. doi:10.1074/jbc.M112.380865

Cibulskis K, Lawrence MS, Carter SL, Sivachenko A, Jaffe D, Sougnez C, Gabriel S, Meyerson M, Lander ES, Getz G. 2013. Sensitive detection of somatic point mutations in impure and heterogeneous cancer samples. Nat Biotechnol 31: 213-219. doi:10.1038/nbt.2514

Czerwińska P, Mazurek S, Wiznerowicz M. 2017. The complexity of TRIM28 contribution to cancer. J Biomed Sci 24: 63. doi:10.1186/s12929-017-0374-4

DePristo MA, Banks E, Poplin R, Garimella KV, Maguire JR, Hartl C, Philippakis AA, del Angel G, Rivas MA Hanna M, et al. 2011. A framework for variation discovery and genotyping using next-generation DNA sequencing data. Nat Genet 43: 491-498. doi:10.1038/ng.806. 
Diets IJ, Hoyer J, Ekici AB, Popp B, Hoogerbrugge N, van Reijmersdal SV, Bhaskaran R, Hadjihannas M, Vasileiou G, Thiel CT, et al. 2019. TRIM28 haploinsufficiency predisposes to Wilms tumor. Int J Cancer 145: 941-951. doi:10.1002/ijc.32167

Dome JS, Huff V. 1993. Wilms tumor predisposition. In GeneReviews ${ }^{\circledR}$ (ed. Pagon RA, Adam MP, Ardinger HH, Wallace SE, et al.), pp. 1993-2020. University of Washington, Seattle.

Dome JS, Fernandez CV, Mullen EA, Kalapurakal JA, Geller JI, HuffV, Gratias EJ, Dix DB, Ehrlich PF, Khanna G, et al. 2013. Children's Oncology Group's 2013 blueprint for research: renal tumors. Pediatr Blood Cancer 60: 994-1000. doi:10.1002/pbc.24419

Friedman JR, Fredericks WJ, Jensen DE, Speicher DW, Huang XP, Neilson EG, Rauscher FJ III. 1996. KAP-1, a novel corepressor for the highly conserved KRAB repression domain. Genes Dev 10: 2067-2078. doi:10 $.1101 /$ gad.10.16.2067

Gadd S, Huff V, Walz A, Ooms A, Armstrong A, Gehrard D, Smith A, Auvil J, Meerzaman D, et al. 2017. A Children's Oncology Group and TARGET initiative exploring the genetic landscape of Wilms tumor. Nat Genet 49: 1487-1494. doi:10.1038/ng.3940

Halliday BJ, Fukuzawa R, Markie DM, Grundy RG, Ludgate JL, Black MA, Skeen JE, Weeks RJ, Catchpoole DR, Roberts AGK, et al. 2018. Germline mutations and somatic inactivation of TRIM28 in Wilms tumour. PLoS Genet 14: e1007399. doi:10.1371/journal.pgen.1007399

lyengar S, Farnham PJ. 2011. KAP1 protein: an enigmatic master regulator of the genome. J Biol Chem 286: 26267-26276. doi:10.1074/jbc.R111.252569

Kim SS, Chen YM, O'Leary E, Witzgall R, Vidal M, Bonventre JV. 1996. A novel member of the RING finger family, KRIP-1, associates with the KRAB-A transcriptional repressor domain of zinc finger proteins. Proc Natl Acad Sci 93: 15299-15304. doi:10.1073/pnas.93.26.15299

Kim WJ, Wittner BS, Amzallag A, Brannigan BW, Ting DT, Ramaswamy S, Maheswaran S, Haber DA. 2015. The WTX tumor suppressor interacts with the transcriptional corepressor TRIM28. J Biol Chem 290: 1438114390. doi:10.1074/jbc.M114.631945

Lek M, Karczewski KJ, Minikel EV, Samocha KE, Banks E, Fennell T, O’Donnell-Luria AH, Ware JS, Hill AJ, Cummings BB, et al. 2016. Analysis of protein-coding genetic variation in 60,706 humans. Nature 536: 285-291. doi:10.1038/nature19057

Li H, Durbin R. 2009. Fast and accurate short read alignment with Burrows-Wheeler transform. Bioinformatics 25: 1754-1760. doi:10.1093/bioinformatics/btp324.

Liu L, Xiao L, Liang X, Chen L, Cheng L, Zhang L, Wu X, Xu Q, Ma C. 2017. TRIM28 knockdown increases sensitivity to etoposide by upregulating E2F1 in non-small cell lung cancer. Oncol Rep 37: 3597-3605. doi:10 3892/or.2017.5638

Magi A, Tattini L, Cifola I, D'Aurizio R, Benelli M, Mangano E, Battaglia C, Bonora E, Kurg A, Seri M, et al. 2013. EXCAVATOR: detecting copy number variants from whole-exome sequencing data. Genome Biol 14: R120. doi:10.1186/gb-2013-14-10-r120

Mahamdallie S, Yost S, Poyastro-Pearson E, Holt E, Zachariou A, Seal S, Elliott A, Clarke M, Warren-Perry M, Hanks S, et al. 2019. Identification of new Wilms tumour predisposition genes: an exome sequencing study. Lancet Child Adolesc Health 3: 322-331. doi:10.1016/S2352-4642(19)30018-5

Micale MA, Embrey BT, Macknis JK, Harper CE, Aughton DJ. 2016. Constitutional 560.49 kb chromosome 2p24.3 duplication including the MYCN gene identified by SNP chromosome microarray analysis in a child with multiple congenital anomalies and bilateral Wilms tumor. Eur J Med Genet 59: 618-623. doi:10.1016/ j.ejmg.2016.10.010

Moosmann P, Georgiev O, Le Douarin B, Bourquin JP, Schaffner W. 1996. Transcriptional repression by RING finger protein TIF1 $\beta$ that interacts with the KRAB repressor domain of KOX1. Nucleic Acids Res 24: 48594867. doi:10.1093/nar/24.24.4859

Saunders CT, Wong WS, Swamy S, Becq J, Murray LJ, Cheetham RK. 2012. Strelka: accurate somatic smallvariant calling from sequenced tumor-normal sample pairs. Bioinformatics 28: 1811-1817. doi:10.1093/ bioinformatics/bts271

Sondka Z, Bamford S, Cole CG, Ward SA, Dunham I, Forbes SA. 2018. The COSMIC Cancer Gene Census: describing genetic dysfunction across all human cancers. Nat Rev Cancer 18: 696-705. doi:10.1038/ s41568-018-0060-1

Walz AL, Ooms A, Gadd S, Gerhard DS, Smith MA, Guidry Auvil JM, Meerzaman D, Chen QR, Hsu CH, Yan C et al. 2015. Recurrent DGCR8, DROSHA, and SIX homeodomain mutations in favorable histology Wilms tumors. Cancer Cell 27: 286-297. doi:10.1016/j.ccell.2015.01.003 


\section{COLD SPRING HARBOR Molecular Case Studies}

\section{TRIM28 congenital predisposition to Wilms' tumor: novel mutations and presentation in a sibling pair}

Colin Moore, Hector Monforte, Jamie K. Teer, et al.

Cold Spring Harb Mol Case Stud 2020, 6: a004796 originally published online July 22, 2020

Access the most recent version at doi: $10.1101 / \mathrm{mcs} .0004796$
Supplementary http://molecularcasestudies.cshlp.org/content/suppl/2020/07/22/mcs.a004796.D Material C1

References This article cites 27 articles, 6 of which can be accessed free at: http://molecularcasestudies.cshlp.org/content/6/4/a004796.full.html\#ref-list-1

License This article is distributed under the terms of the Creative Commons Attribution-NonCommercial License, which permits reuse and redistribution, except for commercial purposes, provided that the original author and source are credited.

Email Alerting Receive free email alerts when new articles cite this article - sign up in the box at the Service top right corner of the article or click here. 